\title{
An Assessment of the Relationship between Nonunion and Device Failure Following the Treatment of Intertrochanteric Fracture, by Dynamic Hip Screw (DHS) Using Arbeitsgemeinschaft fur Osteosynthesfrogen/Orthopedic Trauma Association (A0/OTA) and Dorr Classification
}

\author{
Ali Torkaman', Hamidreza Yazdi'2, Hosein Hamdollahzadeh1, Amin Akbari³, \\ Mehri Yousof Gomrokchi4, Alireza Yousof Gomrokchi1* \\ ${ }^{1}$ Firoozgar Clinical Research Development Center, Iran University of Medical Science, Tehran, Iran \\ ${ }^{2}$ Neuromusculoskeletal Research Center, Firoozgar Hospital, Department of Knee Surgery, Iran University of Medical Science, \\ Tehran, Iran \\ ${ }^{3}$ Health Management and Economics Research Center, Iran University of Medical Sciences, Tehran, Iran \\ ${ }^{4}$ Faculty Member of Islamic Azad University, Abhar Branch, Zanjan, Iran \\ Email: *arugomrokchi@gmail.com
}

How to cite this paper: Torkaman, A., Yazdi, H., Hamdollahzadeh, H., Akbari, A., Yousof Gomrokchi, M. and Yousof Gomrokchi, A. (2017) An Assessment of the Relationship between Nonunion and Device Failure Following the Treatment of Intertrochanteric Fracture, by Dynamic Hip Screw (DHS) Using Arbeitsgemeinschaft fur Osteosynthesfrogen/Orthopedic Trauma Association (AO/OTA) and Dorr Classification. Open Journal of Orthopedics, 7, $32-42$.

http://dx.doi.org/10.4236/ojo.2017.71005

Received: November 13, 2016

Accepted: January 22, 2017

Published: January 25, 2017

\begin{abstract}
Background: Intertrochanteric fractures are of intense interest globally. They are the most frequently operated fracture type, have the highest postoperative fatality rate of surgically treated fractures, and have become a serious health resource issue due to the high cost of care required after injury. A number of problems exist when determining the best option for treatment for intertrochanteric fractures. The classification systems do not work well enough for preoperative planning and the reduction criteria have not been well defined. Methods: All patients who presented to Firoozgar Hospital, Tehran with intertrochanteric fracture, between March 20th 2013 and December 21st 2015, underwent DHS implementation, after 6-month follow-up period. Demographic data, preoperative radiographic fracture, bone quality typing (AO/OTA and Dorr classification), American Society of Anesthesiologists (ASA) score and evaluation of their correlation with the complication of fixation including nonunion and device failure were recorded and analyzed. Result: 101 patients including 54 males (53.5\%) and 47 females (46.5\%) underwent DHS implementation. Mean population age was $73.06 \pm 16.36$ years with an age range of
\end{abstract}


Copyright () 2017 by authors and Scientific Research Publishing Inc. This work is licensed under the Creative Commons Attribution International License (CC BY 4.0).

http://creativecommons.org/licenses/by/4.0/ (c) (i) Open Access
30 to 94 years; the most frequent age period was 76 - 85 years, injured by low-energy trauma mechanism and $23.8 \%$ patients were injured in a highenergy trauma. 56 patients completed the 6-month follow-up evaluation which ranged from 1 to 80 weeks. According to AO/OTA classification, the most common type among the patient population was A2, 27 patients (51.5\%); while the most common group from Dorr classification turned to be group B (39.6\%). Classification by ASA score revealed Class II to be most frequent among the patient population (56.4\%). Nonunion was seen in eight of patients (14.3\%). Three patients (5.4\%) had device failure, two cases showed side plate breakage, and another one had screw cut out. There was no significant relationship between AO/OTA classification with the both complications i.e. the development of device failure $(P=0.85)$ and nonunion $(P=0.99)$. Non-significant correlation was found between Dorr classification with device failure $(P=0.06)$ and nonunion $(P=0.11)$. Conclusion: Regarding recent studies, more effective factor on the outcome is patient's medical condition before surgery compared to the radiographic findings including AO/OTA and Dorr classification.

\section{Keywords}

Device Failure, AO/OTA and Dorr Classification, Dynamic Hip Screw

\section{Introduction}

Intertrochanteric fractures along with other types of hip fractures are among the most common orthopedic complaints especially in the aged population. These impairments impose a great financial burden on orthopedic facilities [1] [2]. This type of fracture is associated with a $20 \%$ bed occupation in orthopedic hospitals [2]. In 1990, it was estimated that $26 \%$ of all hip fractures occurred in Asia; it is now speculated that in years 2025 and 2050 this number will reach $37 \%$ and $45 \%$ respectively [3].

Patients with hip fracture are prone to a high risk of morbidity and mortality. The rate of morbidities and mortalities following the fracture of hip has been reported to be around 15\% - 20\% [4]. Collateral injuries often accompany this type of fracture including urinary tract infections, pneumonia, deep vein thrombosis and pulmonary tract embolism [5]. It has been reported that an efficient surgical intervention and early mobilization after surgery are associated with better function outcomes [6]. That is why the surgical modification is the gold standard for the management of hip fractures [7] [8] [9]. Surgical intervention is associated with substantial pain reduction, while not increasing the risk of mortality [10].

AO/OTA classification is the most referenced in recent scientific articles and is a derivative of the Muller classification. The AO/OTA has nine main "types", however correlation is best with only level 3 designation: 31A1, 31 A2, and 31A3 categories; also there is no lateral radiographic parameter with the AO/OTA 
classification. Generally, the $31 \mathrm{~A} 1$ fracture is the most stable, $31 \mathrm{~A} 2$ more unstable, and the $31 \mathrm{~A} 3$ the most unstable with SHS fixation. Unfortunately, the 4th and 5th subgroups of the classification have not been found to be reliably reproducible in prospective evaluation. There is a higher interobserver agreement with the AO/OTA classification than Evans/Jensen but neither have met the acceptable threshold for reliability.

In the OTA alphanumeric fracture classification, intertrochanteric hip fractures comprise type $31 \mathrm{~A}$. These fractures are divided into three groups, and each group is further divided into subgroups based on obliquity of the fracture line and degree of commination. Group 1 fractures are simple (two-part) fractures, with the typical oblique fracture line extending from the greater trochanter to the medial cortex. The lateral cortex of the greater trochanter remains intact. Group 2 fractures are comminuted with a posteromedial fragment. The lateral cortex of the greater trochanter, however, remains intact. Fractures in this group are generally unstable, depending on the size of the medial fragment. Group 3 fractures are those in which the fracture line extends across both the medial and lateral cortices. This group includes the reverse obliquity pattern.

Three types of morphologic anatomy of the proximal femur were described by Dorr et al. in 1983 for the selection of cemented or non-cemented femoral arthroplasty components. The same rationale applies to implant selection for hip fracture patients. Type A femurs occur primarily in young patients and have a narrow metaphysis, thick cortex, and a high constricting isthmus. Excessive bone removal would be required for intramedullary devices and either a plate-type construct or a smaller diameter reconstruction nail are more bone conserving. Type B femurs have a wider metaphysis and a larger medullary canal but relatively good cortex and isthmus constriction. The type $C$ femur is the most problematic in geriatric populations with hip fractures: A wide metaphysis, wide medullary canal, and loss of the isthmus constriction in association with loss of cortical diaphyseal bone stock.

Surgery is more effective for pain relief and does not result in unacceptable increased mortality or complications. Surgical implant options included plate and screw constructs either nail or screws for the head fixation, nail construct with either nail or screws, external fixation, and arthroplasty. Generically, these options can be grouped to designs with common biomechanical behaviors, techniques, complications, and results.

From the 1980 s to 2000 , SHSs became the gold standard for hip fracture fixation, reinforced by the reports of Clawson, Mulholland, and meta-analysis studies by Parker and Handoll. 174 The device consists of a large fragment side plate attached with $4.5-\mathrm{mm}$ cortical screws to the shaft of the femur with a barrel on the proximal plate for connection with a large threaded screw inserted over a guide wire into the femoral head. These devices, made from stainless steel or titanium alloys, come in varying barrel angles of 125 to 150 degrees with $12.5-\mathrm{mm}$ large diameter lag screws in lengths from 65 to $130 \mathrm{~mm}$. The plates typically used have two to four holes but longer versions are available. They are commer- 
cially available internationally as a generic device from many orthopedic companies.

Watson et al. compared the Medoff plate to a standard SHS in a prospective randomized series of 160 stable and unstable intertrochanteric fractures; follow-up averaged 9.5 months (range: 6 to 26 months). Although stable fracture patterns united without complication in both treatment groups, there was a significantly higher failure rate with use of the SHS for unstable fractures (14\% vs. $3 \%)$.

There has been an ongoing debate regarding the method of surgery and the device of choice for that account; that is while there is no consensus regarding the selection of device among authors. Although there has been an increase in the use of intramedullary devices in the US [11], given the long-standing history of using Dynamic hip screws (DHS) and the fact that they are less expensive and come along with the advantage of more familiarity with surgeons, it seems that the use of this device is still an appropriate choice for the treatment of hip fractures [12].

In this study we aimed to evaluate patients with hip fracture with any type of fracture pattern (according to AO/OTA classification) and proximal femur bone quality (according to Dorr classification) who had undergone surgery using dynamic hip screws. We followed eligible patients and assessed the incidence of complications including nonunion and device failure.

Given the lack of agreement regarding the device of choice for the management of hip fractures, this study could provide the basis for further comparative studies regarding device selection and surgical methods to reach a global consensus.

\section{Material and Method}

A retrospective cohort study of intertrochanteric fracture treated with dynamic hip screw (DHS) was performed. After approved this study in Firoozgar Hospital, the necessary permits were obtained from the Iran University of Medical Sciences and the University Ethics Committee. The authors gave the necessary explanations to patients about the purpose of research, and then they were enrolled in the study after take of oral confirmation. For the purpose of this study, every patient with an intertrochanteric fracture who underwent surgery using DHS from March 20th 2013 to December 21st 2015 who arrived to Firoozgar hospital, Tehran was enrolled in this study. Among 164 patients with intertrochanteric fracture who presented to Firoozgar hospital, 47 patients were not appropriate for DHS application, 16 patients were contraindicated for anesthesia because of medical disease, 101 patients including 54 males (53.5\%) and 47 females (46.5\%) went under DHS implementation. Demographic data, medical history, laboratory data and radiographic findings including fracture type and proximal femoral bone quality were gathered and documented in patient records.

Patients went under surgery after medical stabilization. Using the proper size 
of plates and screws, patient went under implementation of DHS using the conventional method through a lateral skin incision. Surgical details including surgical duration (the duration between induction of anesthesia and transfer into recovery room), blood loss during surgery and transfusion were recorded in patient records.

In the post-op evaluation, additional information including post-op radiographs, time of mobilization and date of discharge were documented. Patients were then discharged with orders regarding wound care, mobilization and training and the time interval for post-op visits. A course of anticoagulants was administered to patients with certain indications.

In the post-op evaluation patients were assessed in clinical visits; also telephone follow-up was performed for patients who could not make it to the clinic. Patients were evaluated for medical complications, mobility status and in case of mortality, the details and the reason for the incidence was carefully documented. Patients whose follow-up period exceeded 6 months were evaluated for union status, device failure.

Gathered data were analyzed using SPSS statistical analysis software (V. 16). The correlation between different variables and parameters like any type of fracture pattern (according to AO/OTA classification) and proximal femur bone quality (according to Dorr classification), device failure, femoral shortening and union was evaluated. A P value of 0.05 and below was determined for identification of statistical significance. Pearson's correlation coefficient was used for the assessment of correlation.

Pre-operative radiographic parameters like Dorr classification, AO/OTA Classification and the neck-shaft angle of the opposite joint were assessed by the surgeon in charge and the chief resident. Assessment was performed in 2 steps using the picture archiving and communication system (PACS). Other radiographic data including TAD and femoral shortening were gathered using the same method.

Device failure was defined as screw breakage, plate breakage, screw cutout and screw protrusion from femoral neck. Nonunion occurs when a fracture has failed to heal in the expected time and is not likely to heal without new intervention Bone healing (union) was evaluated considering focal tenderness, pain with movement and bone "Callus" formation in radiographic imaging.

\section{Result}

Among 164 patients with intertrochanteric fracture who presented to Firoozgar hospital, Tehran, between March 20th 2013 to December 21st 2015, 101 patients including 54 males (53.5\%) and 47 females (46.5\%) went under DHS implementation. Mean population age was $73.06 \pm 16.36$ years with an age range of 30 to 94 years; the most frequent age period was 76 - 85 years.

Injured by a low-energy trauma mechanism and $23.8 \%$ were injured in a high-energy trauma. 56 patients completed the 6 month follow-up period. 14 patients passed away, 1 of whom had made it through the 6 month follow-up pe- 
riod. 32 patients did not commit to the follow-up program. Mean follow-up period for those who passed the 6 month follow-up was 29.8 weeks; all patients received follow-up evaluation which ranged from 1 to 80 weeks. 27 of 56 patients (48.2\%) were followed more than 48 weeks.

According to AO/OTA classification the most common type among the patient population was A2, 27 patients (51.5\%); while A1 was 15 patients (20.8\%) and $\mathrm{A} 3$ was 14 patients (25\%). The most common group from Dorr classification turned to be group B, 21 patients (37.5\%), while type A included 15 patients (26.8\%) and type C included 20 patients (35.7\%). Classification by ASA score revealed Class II to be most frequent among the patient population (56.4\%) (Tables 1-3).

\subsection{Union}

In the follow-up period, nonunion was seen in eight patients (14.3\%). Among various variables that were analyzed for correlation with nonunion, female gender was the only variable to have a significant correlation $(\mathrm{P}=0.023)$. Variables including $\mathrm{AO} / \mathrm{OTA}$ and Dorr classification, were found to be irrelevant

Table 1. Demographic data.

\begin{tabular}{|c|c|c|c|}
\hline Variable & Condition & Count & Percentage \\
\hline \multirow{2}{*}{ Gender } & Male & 54 & $53.5 \%$ \\
\hline & Female & 47 & $46.5 \%$ \\
\hline \multirow{5}{*}{ Age } & Aged Less than 55 Years & 16 & $15.6 \%$ \\
\hline & $56-65$ & 8 & $7.9 \%$ \\
\hline & $66-75$ & 20 & $19.8 \%$ \\
\hline & $76-85$ & 37 & $36.6 \%$ \\
\hline & More than 85 Years & 20 & $19.8 \%$ \\
\hline \multicolumn{2}{|c|}{ Age (Mean \pm Sd) } & \multicolumn{2}{|c|}{$73.07 \pm 36.16$} \\
\hline \multirow{3}{*}{ Follow up Groups } & Completed Follow-Up & 56 & $55.4 \%$ \\
\hline & Died & 13 & $12.9 \%$ \\
\hline & In Follow-Up & 32 & $31.7 \%$ \\
\hline \multirow{2}{*}{$\begin{array}{l}\text { History of Previous } \\
\text { fracture had }\end{array}$} & Positive & 15 & $14.9 \%$ \\
\hline & Negative & 86 & $85.1 \%$ \\
\hline \multirow{2}{*}{ Comorbidity } & positive & 41 & $40.6 \%$ \\
\hline & Negative & 60 & $59.4 \%$ \\
\hline \multirow{4}{*}{ ASA Score } & 1 & 24 & $23.8 \%$ \\
\hline & 11 & 57 & $56.4 \%$ \\
\hline & 111 & 18 & $17.8 \%$ \\
\hline & IV & 2 & $2 \%$ \\
\hline \multirow{2}{*}{ Mechanism } & Low Energy & 77 & $76.2 \%$ \\
\hline & High Energy & 24 & $23.8 \%$ \\
\hline
\end{tabular}


Table 2. Relationship between radiographic finding \& mortality.

\begin{tabular}{|c|c|c|c|c|c|c|c|}
\hline \multirow{2}{*}{ Variable } & \multirow{2}{*}{ Condition } & \multicolumn{2}{|c|}{ Completed Follow-Up } & \multicolumn{2}{|c|}{ Mortality Group } & \multirow{2}{*}{ SE } & \multirow{2}{*}{$\begin{array}{l}\text { Correlation } \\
\text { Coefficient }\end{array}$} \\
\hline & & Count & Percentage & Count & Percentage & & \\
\hline \multirow{3}{*}{ AO/OTA } & A1 & 15 & 26.8 & 2 & $15.4 \%$ & \multirow{3}{*}{$\mathrm{P}=0.68$} & \multirow{3}{*}{0.1} \\
\hline & $\mathrm{A} 2$ & 27 & 48.2 & 7 & $53.8 \%$ & & \\
\hline & A3 & 14 & 25 & 4 & $30.8 \%$ & & \\
\hline \multirow{3}{*}{ Dorr } & A & 15 & 26.8 & 0 & 0 & \multirow{3}{*}{$\mathrm{P}=0.102$} & \multirow{3}{*}{0.12} \\
\hline & B & 21 & 37.5 & 6 & $46.2 \%$ & & \\
\hline & $\mathrm{C}$ & 20 & 35.7 & 7 & $53.8 \%$ & & \\
\hline
\end{tabular}

Table 3. Relationship between variables with union.

\begin{tabular}{|c|c|c|c|c|c|c|}
\hline \multirow{2}{*}{ Variable } & \multirow{2}{*}{ Condition } & \multicolumn{2}{|c|}{ Union } & \multicolumn{2}{|c|}{ Nonunion } & \multirow{2}{*}{ SE } \\
\hline & & Count & Percentage & Count & Percentage & \\
\hline \multirow{5}{*}{ Age } & Aged less than 55 years & 12 & 100 & 0 & 0 & \multirow{5}{*}{$P=0.16$} \\
\hline & $56-65$ & 2 & 100 & 0 & 0 & \\
\hline & $66-75$ & 10 & 71.4 & 4 & $28.6 \%$ & \\
\hline & $76-85$ & 16 & 80 & 4 & $20 \%$ & \\
\hline & More than 85 years & 8 & 100 & 0 & 0 & \\
\hline \multirow{2}{*}{ Gender } & Male & 28 & 96.6 & 1 & $3.4 \%$ & \multirow{2}{*}{$\mathrm{P}=0.023$} \\
\hline & Female & 20 & 74.1 & 7 & $25.9 \%$ & \\
\hline \multirow{3}{*}{ AO/OTA } & $\mathrm{A} 1$ & 13 & 86.7 & 2 & $13.3 \%$ & \multirow{3}{*}{$\mathrm{P}=0.99$} \\
\hline & A2 & 23 & 85.2 & 4 & $14.8 \%$ & \\
\hline & A3 & 12 & 85.7 & 2 & $14.3 \%$ & \\
\hline \multirow{3}{*}{ Dorr } & A & 15 & 100 & 0 & 0 & \multirow{3}{*}{$\mathrm{P}=0.11$} \\
\hline & B & 18 & 85.7 & 3 & $14.3 \%$ & \\
\hline & $\mathrm{C}$ & 15 & 75 & 5 & $25 \%$ & \\
\hline
\end{tabular}

to the development of nonunion ( $\mathrm{P}=0.99$ in AO/OTA classification group and $\mathrm{P}=0.11$ in Dorr classification group).

\subsection{Device Failure}

In the follow-up period, three patients (5.4\%) developed different types of device failure. First case of device failure in our study was a73 years old female with intertrochanteric fracture (A1 OTA classification; Dorr C bone quality classification) treated with DHS application $(\mathrm{TAD}=22)$ after 16 weeks follow up without union suffered to side plate breakage.

Second case of device failure was a 83 years old female with intertrochanteric fracture (A3 OTA classification; Dorr C bone quality classification) treated with 
DHS application $(\mathrm{TAD}=20)$ after 48 weeks follow up with union accrue to screw cut out.

Third case of device failure was a 81 years old female with intertrochanteric fracture (A2 OTA classification; Dorr C bone quality classification)treated with DHS application $(\mathrm{TAD}=17)$ after 10 weeks follow up without union accrue to side plate breakage.

Among of fracture pattern (according to AO/OTA classification) and proximal femur bone quality (according to Dorr classification), none was found to be significantly related to the development of device failure $(\mathrm{P}=0.85$ in AO/OTA classification group and $\mathrm{P}=0.06$ in Dorr classification group) (Table 4).

\section{Discussion}

\subsection{Union}

The incidence of nonunion was $14.3 \%$ in this study while Yeganeh et al. had reported a $14.8 \%$ for DHS implantation and $3.7 \%$ of which associated with intramedullary implements rate that was similar to our finding [13]. We found a significant correlation between the incidence of nonunion and the female gender, which we could not explain.

A previous study by Setibudy T. had reported the incidence of nonunion to be $1.4 \%$, all of which had occurred in patients with signs of an unstable fracture in

Table 4. Device failure.

\begin{tabular}{|c|c|c|c|c|c|c|}
\hline \multirow{2}{*}{ Variable } & \multirow{2}{*}{$\begin{array}{l}\text { Device Failure } \\
\text { Condition }\end{array}$} & \multicolumn{2}{|c|}{ Positive } & \multicolumn{2}{|c|}{ Negative } & \multirow{2}{*}{ SE } \\
\hline & & Count & Percentage & Count & Percentage & \\
\hline \multirow{5}{*}{ Age } & Aged less than 55 years & 0 & 0 & 12 & $100 \%$ & \multirow{5}{*}{$\mathrm{P}=0.72$} \\
\hline & $56-65$ & 0 & 0 & 2 & $100 \%$ & \\
\hline & $66-75$ & 1 & $7.1 \%$ & 13 & $92.9 \%$ & \\
\hline & $76-85$ & 2 & $9.5 \%$ & 19 & $90.5 \%$ & \\
\hline & More than 85 years & 0 & 0 & 8 & $100 \%$ & \\
\hline \multirow{2}{*}{ Gender } & Male & 0 & 0 & 29 & $100 \%$ & \multirow{2}{*}{$\mathrm{P}=0.11$} \\
\hline & Female & 3 & $10.7 \%$ & 25 & $89.3 \%$ & \\
\hline \multirow{3}{*}{ AO/OTA } & $\mathrm{A} 1$ & 1 & $6.7 \%$ & 14 & $93.3 \%$ & \multirow{3}{*}{$\mathrm{P}=0.85$} \\
\hline & A2 & 1 & $3.6 \%$ & 27 & $96.4 \%$ & \\
\hline & A3 & 1 & $7.1 \%$ & 13 & $92.9 \%$ & \\
\hline \multirow{3}{*}{ Dorr } & A & 0 & 0 & 15 & $100 \%$ & \multirow{3}{*}{$\mathrm{P}=0.06$} \\
\hline & B & 0 & 0 & 21 & $100 \%$ & \\
\hline & $\mathrm{C}$ & 3 & $14.3 \%$ & 18 & $85.7 \%$ & \\
\hline \multirow{2}{*}{ Mechanism } & Low Energy & 3 & $7.5 \%$ & 37 & $92.5 \%$ & \multirow{2}{*}{$\mathrm{P}=0.54$} \\
\hline & High Energy & Count & Percentage & Count & Percentage & \\
\hline
\end{tabular}

This study shows that age, gender and mechanism of injury have not any significant relationship with device failure but this result is indeterminate. 
radiography [14]. This is while the rate of nonunion was higher in our study and it did not relate to the type of fracture.

Liu C. et al. reported on 22 patients with intertrochanteric fracture treated with DHS from 2006 to 2010 primary healing was observed in all cases. All cases were followed up 6 - 17 months (mean, 14 months). Union of fracture was observed at 12 - 16 weeks (mean, 13.6 weeks); no fracture or internal fixation loosening occurred [15].

\subsection{Screw Cutout and Device Failure}

In our study, there were two device failure and one screw cutout in period of follow up. The mean of TAD was $22.57(\mathrm{SD}=5.92)$ that has no correlation with device failure.

The rate of implant malfunction was $5.4 \%$ in this study, while Parker and Handoll had reported a 5\% incidence in a previous study [10]. This rate was reported to be $1.5 \%$ and $2.6 \%$ and $3.6 \%$ in studies by Zhang and Chan and Setibudy, respectively [16].

We found the correlation between fracture type and device failure to be non-significant; the same result had been reported by Setibudy T. et al. in their study.

Parker et al. reported 5\% device failure in patient with extra capsular fracture that most common of them was shaft medicalization that was similar to our finding but in our study, the most common pattern of device failure was side plate breakage (two patients), and only one screw cutout [10].

Im G. I. et al. demonstrated that increased age $(\mathrm{P}=0.01)$ and commination of the lateral cortex $(\mathrm{P}=0.0001)$ were factors significantly associated with excessive displacement [17]. These 2 factors had a high degree of correlation $(r=0.76)$. In their study lose of reduction was $15 \%$ while in our study, fourteen patients had lateral cortex fracture (25\%) that only one of them suffered to device failure (7.1\%) and correlation between high grade unstable intertrochanteric fracture and device failure was non-significant $(\mathrm{P}=0.85)$.

Zhang et al. showed 1.5\%; Qiang et al. 2.6\%; Setiobudi et al. 3.6\% device failure in their patients [16].

Chua et al. studied on 63 patients underwent fixation for unstable intertrochanteric fracture (AO/OTA type A2 and A3) using the PFNA $(\mathrm{n}=25)$ or DHS $(\mathrm{n}=38)$; and reported that there were 3 complications (2.6\% device failure) [18]. Two patients treated with PFNA had blade cut-out, owing to poor fracture reduction. One patient treated with DHS had screw cut-out and subsequently developed a vascular necrosis of the femoral head.

Leung et al. studied on 35 men and 65 women, aged 47 to 100 (mean, 83) years, who underwent fixation with a DHS blade for A1 $(n=47)$ and A2 $(n=53)$ intertrochanteric hip fractures after a low-energy injury. At the one-year follow-up, 81 patients were available, and all fractures had healed without various deformities [19]. There was one loss of fixation (1\% device failure) secondary to a non-traumatic sub-capital fracture at 3 months, for which a bipolar hemi-arthro- 
plasty was performed.

Dhamangaonkar et al. studied on 15 men and 5 women, aged 32 to 78 (mean, 55) years, who were randomized to the proximal femoral locking plate group, whereas 14 men and 6 women aged 38 to 75 (mean, 59) years were randomized to the conventional 135-degree DHS group [20]. Medicalization of the shaft occurred in 0 and 15 patients $(\mathrm{P}<0.0001)$; varus collapse occurred in 2 and 5 patients $(\mathrm{P}=0.408)$; and implant cut-out occurred in one patient in each group (5\% device failure).

Emami et al. studied 60 patients with intertrochanteric fractures, in the range of 45 - 60 years old, who were randomly divided into DHS and bipolar groups and $5 \%$ failure was reported in DHS group [21].

Given the lack of a consensus regarding the device of choice for the management of hip fractures, it seems that neither the radiographic nor demographic parameters can be relied upon to predict the outcome in patients undergoing surgery. We suggest that a combination of parameters including surgeon's experiment, clinical, radiographic and para-clinical characteristics might elicit a more accurate outcome and could effectively guide the process of treatment and device selection as well as other surgical specifications.

\section{Acknowledgements}

We would like to thank Iran University of Medical Sciences for all their support and also the participants and everyone who helped us in the completion of this project.

\section{References}

[1] Court-Brown, C.M. and Caesar, B. (2006) Epidemiology of Adult Fractures: A Review. Injury, 37, 691-697. https://doi.org/10.1016/j.injury.2006.04.130

[2] Leighton, R.K. (2006) Fractures of the Neck of the Femur. In: Bucholz, R.W., Heckman, J.D. and Court-Brown, C.M., Eds., Fractures in Adults, 6th Edition, Lippincott, Philadelphia, 1753-1788.

[3] Little, N.J., Verma, V., Fernando, C., et al. (2008) A Prospective Trial Comparing the Holland Nail with the Dynamic Hip Screw in the Treatment of Intertrochanteric Fractures of the Hip. Journal of Bone and Joint Surgery (British), 90, 1073-1078.

[4] Abrahamsen, B., van Staa, T., Ariely, R., et al. (2009) Excess Mortality Following Hip Fracture: A Systematic Epidemiological Review. Osteoporosis International, 20, 1633-1650. https://doi.org/10.1007/s00198-009-0920-3

[5] Watson-Jones, R. (2009) Fracture Treatment. Vol. 29, 7th Edition.

[6] Talkowski, J.B., Lenze, E.J., Munin, M.C., et al. (2009) Patient Participation and Physical Activity during Rehabilitation and Future Functional Outcomes in Patients after Hip Fracture. Archives of Physical Medicine and Rehabilitation, 90, 618-622. https://doi.org/10.1016/j.apmr.2008.10.024

[7] Bolhofner, B.R., Russo, P.R. and Carmen, B. (1999) Results of Intertrochanteric Femur Fractures Treated with a 135-Degree Sliding Screw with a Two-Hole Side Plate. Journal of Orthopaedic Trauma, 13, 5-8. https://doi.org/10.1097/00005131-199901000-00002

[8] Lee, Y.-S., Huang, H.-L., Lo, T.-Y. and Huang, C.-R. (2007) Dynamic Hip Screw in 
the Treatment of Intertrochanteric Fractures: A Comparison of Two Fixation Methods. International Orthopaedics, 31, 683-688.

https://doi.org/10.1007/s00264-006-0248-y

[9] Lyons, A.R. (1997) Clinical Outcomes and Treatment of Hip Fractures. American Journal of Medicine, 103, 51S-63S.

[10] Handoll, H.H.G. and Parker, M.J. (2008) Conservative versus Operative Treatment for Hip Fractures in Adults. Cochrane Database of Systematic Reviews, No. 3, CD000337. https://doi.org/10.1002/14651858.cd000337.pub2

[11] Handoll, H.H.G., Farrar, M.J., McBirnie, J., et al. (2002) Heparin, Low Molecular Weight Heparin and Physical Methods for Preventing Deep Vein Thrombosis and Pulmonary Embolism Following Surgery for Hip Fractures. Cochrane Database of Systematic Reviews, No. 4, CD000305.

[12] Yechiel, G. (2012) The Pantrochanteric Hip Fracture: An Iatrogenic Entity. Journal of Orthopaedic Trauma, 26, 197-199. https://doi.org/10.1097/BOT.0b013e318245868c

[13] Yeganeh, A., Taghavi, R. and Moghtadaei, M. (2016) Comparing the Intramedullary Nailing Method versus Dynamic Hip Screw in Treatment of Unstable Intertrochanteric Fractures. Medical Archives, 70, 53-56.

[14] Setiobudi, T., Ng, Y.H., Lim, C.T., Liang, S., Lee, K. and Das De, S. (2011) Clinical Outcome Following Treatment of Stable and Unstable Intertrochanteric Fractures with Dynamic Hip Screw. Annals of the Academy of Medicine-Singapore, 40, 482.

[15] Liu, C., Li, Q., Yang, J. and Jin, A. (2011) Treatment of Intertrochanteric Fractures with Dynamic Hip Screw and Femoral Neck Antirotation Screw. Chinese Journal of Reparative and Reconstructive Surgery, 25, 3346.

[16] Huang, S.G., Chen, B., Zhang, Y., Nie, F.F., Ju, L., Li, M. and Zhang, Y.H. (2015) Comparison of the Clinical Effectiveness of PFNA, PFLCP, and DHS in Treatment of Unstable Intertrochanteric Femoral Fracture. American Journal of Therapeutics.

[17] Im, G.I., Shin, Y.W. and Song, Y.J. (2005) Potentially Unstable Intertrochanteric Fractures. Journal of Orthopaedic Trauma, 19, 5-9. https://doi.org/10.1097/00005131-200501000-00002

[18] Chua, I.T., Rajamoney, G.N. and Kwek, E.B. (2013) Cephalomedullary Nail versus Sliding Hip Screw for Unstable Intertrochanteric Fractures in Elderly Patients. Journal of Orthopaedic Surgery, 21, 308-312.

[19] Leung, F., Gudushauri, P., Yuen, G., Lau, T.W., Fang, C. and Chow, S.P. (2012) Dynamic Hip Screw Blade Fixation for Intertrochanteric Hip Fractures. Journal of Orthopaedic Surgery, 20, 302-306.

[20] Dhamangaonkar, A.C. (2013) Proximal Femoral Locking Plate versus Dynamic Hip Screw for Unstable Intertrochanteric Femoral Fractures. Journal of Orthopaedic Surgery, 21, 317-322. https://doi.org/10.1177/230949901302100311

[21] Emami, M., Manafi, A., Hashemi, B., Nemati, A. and Safari, S. (2013) Comparison of Intertrochanteric Fracture Fixation with Dynamic Hip Screw and Bipolar Hemiarthroplasty Techniques. Archives of Bone and Joint Surgery, 1, 14-17. 
Submit or recommend next manuscript to SCIRP and we will provide best service for you:

Accepting pre-submission inquiries through Email, Facebook, LinkedIn, Twitter, etc. A wide selection of journals (inclusive of 9 subjects, more than 200 journals)

Providing 24-hour high-quality service

User-friendly online submission system

Fair and swift peer-review system

Efficient typesetting and proofreading procedure

Display of the result of downloads and visits, as well as the number of cited articles Maximum dissemination of your research work

Submit your manuscript at: http://papersubmission.scirp.org/

Or contact ojo@scirp.org 